\title{
Efeito de Ajustes Contratuais sobre a Eficiência de Custo de Propriedades Citrícolas do Estado de São Paulo ${ }^{1}$
}

\author{
Marcelo José Carrer² e Hildo Meirelles de Souza Filho ${ }^{3}$
}

\begin{abstract}
Resumo: Este trabalho teve o objetivo principal de analisar o efeito da ocorrência de ajustes contratuais não antecipados sobre a eficiência de custo de propriedades citrícolas. Como referencial teórico, utilizou-se a Nova Economia Institucional. Foram coletados dados primários referentes ao ano-safra 2013/14 junto a uma amostra aleatória de 98 propriedades rurais localizadas no estado de São Paulo, Brasil. Os dados foram analisados por meio de um modelo de fronteira estocástica de custo com determinantes de ineficiência, conforme proposto por Battese e Coelli (1995). Verificou-se que a ocorrência de ajustes contratuais nos anos-safra 2011/12, 2012/13 e 2013/14 teve efeito negativo e estatisticamente significativo sobre a eficiência de custo das propriedades. As variáveis de controle utilizadas no modelo econométrico (diversificação da produção e adoção de ferramentas de gestão) também se mostraram importantes para explicar os diferenciais de eficiência de custo das propriedades. Os resultados comprovam as hipóteses estabelecidas em torno das variáveis e têm importantes implicações para a formulação de políticas públicas e estratégias de gestão.
\end{abstract}

Palavras-chaves: citricultura, eficiência de custo, estruturas de governança, contratos, instituições.

Abstract: This paper aims to analyze the effect of unanticipated contractual adjustments on the cost efficiency of citrus farms. The theoretical framework was based on the New Institutional Economics. Primary data for the crop year 2013/14 were collected from a representative random sample of 98 citrus farms. The single stage model developed by Battese and Coelli (1995) was used to estimate the stochastic cost frontier and the determinants of the efficiency of farms. It was found that the occurrence of contractual adjustments in 2011/12, 2012/13 and 2013/14 had a negative and statistically significant effect on the cost efficiency of citrus farms. The control variables used in the econometric model (production diversification and adoption of management tools) also proved to be

1. Data de submissão: 22 de abril de 2016. Data de aceite: 29 de outubro de 2017.

2. Instituto Federal de Educação, Ciência e Tecnologia de São Paulo, São Carlos, São Paulo, Brasil. E-mail: marcelocarrer@ifsp.edu.br

3. Departamento de Engenharia de Produção, Universidade Federal de São Carlos, São Carlos, São Paulo, Brasil. E-mail: hildo@dep.ufscar.br 
important to explain the cost efficiency differentials. The empirical results confirm the established hypotheses about the variables and have important implications for the formulation of public policies and management strategies.

Key-words: citrus industry, cost efficiency, governance structures, contracts, institutions.

Classificação JEL: D22, D24, L22, L25.

DOI: http://dx.doi.org/10.1590/1234-56781806-94790560301

\section{Introdução}

Disputas nas transações entre agentes econômicos são, em grande medida, tributárias das dificuldades de realinhamento e adaptação de contratos diante de distúrbios não antecipados (WILLIAMSON, 1996). O mesmo ocorre quando há ações oportunistas com objetivo de capturar quase-rendas (KLEIN et al., 1978; WILLIAMSON, 1991; ROOKS et al., 2006). Tais situações ocorrem com mais frequência quando existe elevada especificidade de ativo, assimetria de informação e assimetria de poder de barganha entre os agentes econômicos envolvidos na transação (PERRY, 1989; ROOKS et al., 2006). ${ }^{4}$ Ademais, diante de um ambiente institucional instável, no qual regras formais e informais não estão bem estabelecidas ou são simplesmente ignoradas pelos agentes, a possibilidade da ocorrência de ajustes contratuais ex-post é significativamente maior (NORTH, 1994).

Todas as condições mencionadas no parágrafo anterior estão presentes, com maior ou menor intensidade, no sistema agroindustrial (SAG) citrícola brasileiro. Esse SAG é caracterizado pela existência de um número grande de agricultores com baixa capacidade

4. Quase-renda pode ser definida como a diferença entre o valor de um ativo na transação em que ele está envolvido e o valor deste mesmo ativo em uma outra transação (PERRY, 1989). Como é bastante difícil renegociar ativos específicos a uma determinada transação em outras transações, tal diferença é positivamente relacionada com a especificidade do ativo. No caso de transações em que o poder de barganha é assimétrico, a captura das quase rendas pelo agente com maior poder de barganha é facilitada. de organização horizontal vis à vis um pequeno número de grandes empresas processadoras, caracterizando-se um oligopsônio. As empresas têm adotado um conjunto de estratégias comerciais que são representativas do seu poder nas negociações junto aos agricultores, tais como aumento na proporção da produção própria de laranja (integração vertical parcial), atraso nas compras da laranja dos fornecedores independentes e diferenciação de preços segundo o tamanho do fornecedor (MARINO e AZEVEDO, 2003; SOUZA FILHO e PAULILLO, 2005; PAULILLO et al., 2007; FIGUEIREDO et al., 2013; SOUZA FILHO et al., 2013). ${ }^{5}$

Nos anos-safra 2011/12 e 2012/13, houve expansão na oferta de laranja devido às boas condições climáticas, resultando em queda no preço da caixa de laranja abaixo da média histórica. As indústrias passaram a solicitar renegociações de preços e quantidades previamente estabelecidas em contratos de compra de laranja, causando queixas por parte dos citricultores e suas organizações. Muitos citricultores foram levados a acatar involuntariamente os ajustes e a reconsiderar suas decisões de produção e de continuidade na atividade. Em grande medida, o citricultor encontra-se fragilizado nas transações devido às especificidades física e temporal do produto (laranja) e à presença de poucos

5. Essas práticas comerciais foram reconhecidas no parecer do relator do Conselho Administrativo de Defesa Econômica (Cade) no processo de no $08012.003065 / 2012-21$ (Constituição do Consecitrus pela CitrusBR e pela SRB), no qual se estabelece a criação do Consecitrus (conselho de representantes dos citricultores e indústrias processadoras de suco de laranja). Para mais detalhes, ver Ato de Concentração no 08012.003065/2012-21 (2014). 
compradores capazes de absorver a grande produção do cinturão citrícola. Há elevada dependência das grandes processadoras (MELLO e PAULILLO, 2009). Além disso, não há mecanismo de arbitragem e o custo judicial de um eventual litígio é elevado. Nessas condições, a credibilidade do citricultor em relação aos compromissos assumidos pelos compradores de laranja passa a ter grande importância nas suas decisões de produção. Pode-se, portanto, levantar a seguinte questão: a ocorrência desses ajustes contratuais afeta a credibilidade em relação aos contratos e, por consequência, a eficiência econômica das propriedades citrícolas?

O principal objetivo deste trabalho é testar empiricamente o efeito da ocorrência de ajustes nos contratos de compra e venda da laranja sobre a eficiência de custo das propriedades citrícolas ${ }^{6}$. A hipótese central do estudo é a de que os ajustes contratuais ocorridos resultaram em aumento de custos de transação não antecipados, aumento de incerteza e desincentivos para os produtores, resultando em queda de investimentos e esforços gerenciais; afetando a alocação e o uso dos fatores de produção. O principal resultado do trabalho mostra que há relação negativa e estatisticamente significativa entre a ocorrência de ajustes contratuais nas transações de venda de laranja e a eficiência de custo das propriedades citrícolas, corroborando com a hipótese central. Ademais, constatou-se que uso de ferramentas de gestão e a diversificação da produção, variáveis de controle utilizadas no modelo econométrico, também são importantes para explicar os diferenciais de eficiência de custo das propriedades analisadas.

6. A medida de eficiência econômica de custo pode ser obtida pela razão entre o custo total mínimo para operar determinado volume de produção diante da tecnologia disponível e o custo total observado da firma ao operar esse mesmo volume de produção. A eficiência de custo pode ser desmembrada em dois componentes: (i) eficiência técnica orientada para o uso dos fatores/insumos e (ii) eficiência alocativa. A eficiência técnica orientada para os insumos implica em operar determinado nível de produção com a menor dotação possível de fatores diante da tecnologia de produção disponível. A eficiência alocativa, por sua vez, ocorre quando a firma escolhe a combinação ótima dos fatores de produção diante dos preços relativos dos mesmos. Nesse ponto, a inclinação da tangente da isoquanta (relação entre os produtos marginais dos fatores) é igual à inclinação da isocusto (relação entre os preços dos fatores). Portanto, a ineficiência de custo pode resultar de ineficiência no uso e/ou na alocação dos fatores de produção.
Além dessa introdução, o artigo está dividido em mais quatro seções. A próxima seção apresenta o referencial teórico adotado para embasar a principal hipótese de pesquisa. A seção três apresenta a amostra, as variáveis e o modelo econométrico adotado para realizar as análises. Na quarta seção são apresentados e discutidos os resultados da análise empírica. Por fim, a quinta seção apresenta alguns comentários finais.

\section{Referencial teórico e hipótese central}

Esse artigo utiliza-se do referencial teórico da Nova Economia Institucional (NEI) para analisar o impacto da ocorrência de ajustes contratuais na eficiência de custo dos citricultores. A NEI destaca a importância do ambiente institucional e a sua influência sobre os custos de transação ex ante e ex post; aspectos fundamentais para determinar a alocação dos recursos no sistema econômico. Portanto, há uma importante relação entre o ambiente institucional e a eficiência das firmas que operam nesse ambiente. Para North (1994), as instituições são restrições e sistemas sociais de regras e comportamento construídos e compartilhados pela sociedade. As instituições moldam e determinam as interações entre os agentes econômicos, sendo formadas por um conjunto de regras formais (leis, normas, constituições, regras de diretos de propriedade etc.), informais (códigos de conduta, regras sociais de comportamento, hábitos estabelecidos etc.) e pelas suas características de enforcement.

Como as instituições fornecem os suportes regulatório, normativo e coercitivo para as relações econômicas e sociais, elas afetam diretamente o comportamento $^{7}$ e as decisões dos agentes, os custos de troca e transformação e, consequentemente, a alocação dos recursos produtivos. As decisões de investimento que a longo prazo determinam o desempenho das firmas são condicionadas às expectativas de apropriação dos retornos do investimento ao longo do tempo. Por sua vez, os instrumentos formais e informais de

7. Segundo Dequech (2013), as instituições, ao afetar o comportamento dos indivíduos, exercem quatro diferentes papéis/funções, quais sejam: (i) restritivo, (ii) cognitivo, (iii) motivacional e (iv) emocional. Portanto, as instituições podem tanto restringir as ações individuais por meio de regras e sanções como também influenciar as formas como os indivíduos processam informações e tomam decisões sociais e econômicas. 
enforcement dos contratos são mecanismos de garantia dos direitos de apropriação dos retornos de um investimento produtivo. Portanto, tais instrumentos têm relação direta com o desempenho das firmas (ORELLANO et al., 2015).

Após o trabalho pioneiro de North (1994), alguns estudos se preocuparam em identificar empiricamente a relação entre o ambiente institucional e o desempenho de um conjunto de firmas e/ou países (BRASSELLE et al., 2002; KLEIN e LUU, 2003; FULGINITI et al., 2004; BOWEN e DECLERCQ, 2008; YASAR et al., 2011; ORELLANO et al., 2015; MICHLER e SHIVELY, 2015). Tais estudos compartilham do argumento de que as instituições formais (sistema judiciário, regras de direitos de propriedade e regras para fazer negócios, por exemplo) e informais (códigos sociais de conduta comercial, redes sociais de produtores, e hábitos, por exemplo) fornecem todas as regras para a operação das firmas e para as relações comerciais entre firmas, determinando, em última instância, as estratégias e os custos de operação e transação desses agentes econômicos. Por exemplo, em um ambiente institucional no qual os contratos sejam totalmente respeitados ou que existam soluções judiciais eficientes para o não cumprimento de contratos, as firmas teriam incentivos para desenvolver estruturas mais eficientes de alocação de recursos e operariam com custos de produção e transação mais baixos. Nesse caso, existem incentivos e segurança para planejar no longo prazo e realizar investimentos em ativos fixos, o que exerce impacto positivo na eficiência econômica das firmas. Já no caso de não estarem bem estabelecidos os mecanismos de enforcement dos contratos e/ou de ajustes contratuais pelos agentes, as firmas encontrariam insegurança, incerteza e restrições para alocar seus recursos de forma ótima, operando com altos custos de produção e transação e com baixa eficiência.

Williamson (1985, 1996) analisou as transações entre os agentes com um enfoque mais microeconômico. Ao propor suas três formas básicas de coordenação eficiente das transações - mercado clássico (spot), formas híbridas e hierarquia -, considerou a existência de três tipos de contratos. No mercado clássico (spot), em que a transação não é específica e não há esforço para sustentar a repetição da relação, os contratos clássicos são adotados. Nesse caso, a identidade das partes é irrelevante nas transações. Compradores e vendedores não possuem relação de dependência uns dos outros, a troca de parceiros acarreta custos negligenciáveis, as transações tendem a ser extremamente monetizadas, e a relação contratual é interpretada de forma extremamente legalista.

No outro extremo está a integração vertical ou hierarquia, que é utilizada em transações recorrentes e na presença de ativos altamente específicos. As transações são trazidas para dentro da firma e submetidas à hierarquia interna. Essa forma de organização é mais elástica e adaptável diante de distúrbios. O contrato implícito nesse tipo de transação é o de forbearance ${ }^{8}$. As partes resolvem suas disputas internamente, tendo a hierarquia como corte de apelação. Nesse caso, a adaptação é facilitada devido ao poder de fiat.

As formas híbridas são de maior importância para o presente artigo, pois são utilizadas quando há investimento em ativos específicos, as transações são recorrentes, mas não há incentivos suficientes para trazer a transação para dentro da firma (integração vertical). Nas formas híbridas, as transações são estabelecidas por meio de contratos neoclássicos, em que as partes mantêm autonomia, mas há dependência bilateral. A identidade das partes assume certa importância em casos de término prematuro ou má adaptação que causem ônus para uma ou ambas as partes. Na ocorrência de distúrbios não antecipados, os contratos podem ser ajustados com maior facilidade, permitindo o realinhamento e a restauração da eficiência. As partes rejeitam o contrato clássico e preferem o contrato neoclássico porque esse último favorece a continuidade da relação e promove adaptação.

É importante destacar os tipos de distúrbios não antecipados e as possibilidades de adaptações a que estão sujeitos os contratos neoclássicos em formas híbridas de coordenação. Williamson (1996) sugere três tipos de distúrbios: não consequentes, consequentes e altamente consequentes. Distúrbios não consequentes são pequenos desvios de uma condição de equilíbrio eficiente e não justificam o custo de um possível ajustamento. O ganho líquido de um realinhamento seria negativo, dado que solicitações de ajustamento devem ser justificadas e estão sujeitas a revisões, cujos custos ultrapassam os ganhos.

8. Do inglês forbearance law. A tradução literal para o inglês é tolerância, embora seja mais apropriado se utilizar subordinação, dado que o termo está associado ao poder de fiat na relação. 
Em situações de distúrbios consequentes, ao contrário, o ganho líquido de um realinhamento é positivo para uma ou ambas as partes. Distúrbios consequentes são tratados de forma mais eficiente em contratos neoclássicos, os quais comtemplam a possibilidade de ajustamento em situações não antecipadas, estabelecem zonas de tolerância, abertura de informações, bem como formas de arbitragem no caso de as partes não alcançarem voluntariamente um acordo.

Em que pese a vantagem de se estabelecerem ajustes, a adaptabilidade dos contratos neoclássicos não é indefinidamente elástica. Se os distúrbios forem altamente consequentes, contratos neoclássicos podem gerar forte tensão entre as partes. A arbitragem, além de ser custosa, pode não solucionar disputas, dando lugar ao litígio. Nesses casos, o realinhamento contratual cede lugar a uma quebra da relação. As partes possuem autonomia para renunciar as propostas de acordo, bem como não repetir a transação.

Williamson (1996) chama atenção para situações em que os ajustes são realizados de forma rotineira, sempre que houver adversidade e sem qualquer restrição. Nesses casos, não haverá incentivo para conduzir a transação por meio de contratos neoclássicos, para realizar escolhas tecnológicas criteriosas, para compartilhar riscos de forma eficiente e para evitar a adversidade. A seguir, discute-se a relação entre a ocorrência de ajustes contratuais e a eficiência de custo na produção citrícola e apresenta-se a principal hipótese do estudo.

\subsection{Ocorrência de ajustes contratuais e eficiência econômica no SAG citrícola}

O SAG citrícola é caracterizado por elevado grau de concentração industrial e grande capacidade de organização da agroindústria processadora frente a milhares de citricultores com pouco ou nenhum poder de mercado e com baixa capacidade de organização (PAULILLO et al., 2007; FIGUEIREDO et al., 2013). Outra característica desse SAG é a assimetria informacional e de poder de barganha entre agricultores e agroindústria processadora (AZEVEDO, 1996; SOUZA FILHO e PAULILLO, 2005; PAULILLO et al., 2007; FIGUEIREDO et al., 2013). Na condição de formadora de estoques, a indústria processadora pode influenciar a formação de preços e outras condições comerciais nas transações com os citricultores. Ademais, por internalizar cerca de $40 \%$ do seu suprimento em pomares próprios, a indústria tem informação privilegiada sobre previsões de safra e outros aspectos relacionados à produção de laranja (conhecimento de padrões de qualidade, produtividade e de aspectos tecnológicos da produção). Essas informações podem ser utilizadas para a obtenção de vantagens comerciais (por exemplo, diferenciação de preço e qualidade nas compras da fruta) nas transações junto aos fornecedores independentes. Azevedo (1996) já havia observado que a estratégia de integração vertical poderia ser utilizada como um meio de obter informação relevante ao processo de barganha, gerando efeitos distributivos na cadeia produtiva. Tal estratégia se intensificou nos anos 2000, chegando aos cerca de $40 \%$ de pomares próprios da indústria supracitados.

Historicamente, são comuns as queixas de citricultores sobre ajustes unilaterais de contratos, que levam à alteração dos parâmetros pré-determinados. Tal conduta estaria influenciando negativamente a viabilidade econômica da atividade citrícola (PAULILLO e ALMEIDA, 2009; FIGUEIREDO et al., 2013). Dentre os principais tipos de ajustes contratuais apontados pelos citricultores, podem-se mencionar: i) alteração no preço acordado; ii) retardamento da recepção da fruta; iii) dilatamento no prazo para pagamento; iv) aquisições abaixo da quantidade contratada; v) não aquisição de toda a quantidade contratada (SOUZA FILHO e PAULILLO, 2005).

No contexto teórico apresentado por Williamson (1996), poder-se-ia afirmar que esses ajustes são realizados de forma rotineira, na ocorrência de qualquer adversidade e sem muita restrição. Não haveria, então, mais sentido conduzir as transações por meio desses contratos, pois os compromissos assumidos não seriam mais críveis. Portanto, citricultores não teriam mais incentivo para realizar transações nessas condições e abandonariam a atividade diante de ausência de melhor governança para transações. Em que pese essa argumentação, o presente artigo não examinará essa possibilidade devido à ausência de dados a respeito de ajustes em contratos por um período mais longo. Assume-se que essa seria uma condição necessária para uma análise dos efeitos dos ajustes rotineiros.

Entretanto, dados primários obtidos para anos-safra 2011/12, 2012/13 e 2013/14, que compreendem um período de forte expansão da produção, permitem realizar uma avaliação do efeito de um distúrbio 
(crescimento da produção). Se considerarmos que o crescimento da produção foi inesperado, devido a condições climáticas excepcionais, então se pode tratar esse distúrbio como consequente, conforme Williamson (1996). Entretanto, dada a saída de muitos citricultores da atividade, poder-se-ia tratá-lo como distúrbio altamente consequente. Nesse caso, as alterações contratuais levaram à quebra da relação. Citricultores, diante da possibilidade de um litígio custoso, tomariam a decisão de não repetir a transação, deixando a atividade.

Pode-se estabelecer a hipótese de que a ocorrência do distúrbio e dos ajustes contratuais solicitados aumentaria os custos de transação para os citricultores, geraria insegurança, desincentivos e redução nos esforços gerenciais na alocação dos recursos e na adoção de novas tecnologias. A hipótese de pesquisa do presente estudo, dado o seu caráter empírico, é a seguinte: os citricultores afetados por um maior número de ajustes contratuais na venda da laranja (redução de preços, redução de quantidade, retardamento da recepção, dilatamento no prazo de pagamento, redução na quantidade contratada e não aquisição) operam suas propriedades rurais com menor eficiência de custo.

A hipótese se fundamenta no argumento de que a ocorrência de ajustes contratuais nos últimos três anos-safra se refletiu em insegurança e incerteza para os produtores. A capacidade dos contratos de gerar incentivos críveis foi reduzida. Consequentemente, os citricultores deixaram de realizar investimentos na produção (insumos, tecnologia e ativos fixos) e em gestão (alocação de recursos e uso de novas práticas gerenciais). Como a citricultura é caracterizada por elevado custo de saída (cultura permanente com elevado investimento imobilizados), muitos citricultores continuam repetindo a transação ainda por algumas safras, mas com baixa eficiência técnica e alocativa.

\section{Metodologia}

\subsection{Modelo de fronteira estocástica de custo}

Para testar a hipótese central estabelecida e analisar outros fatores determinantes da eficiência das propriedades citrícolas, foi feita a estimativa econométrica de uma fronteira estocástica de custo. O modelo econométrico, em sua forma genérica, pode ser descrito como:

$$
\ln C_{i}=C\left(y_{i}, w_{i}, \beta\right)+v_{i}+u_{i}
$$

em que $C_{i}$ é o custo total de produção da i-ésima firma; $C($.) é uma função custo apropriada (translog ou CobbDouglas, por exemplo); $y_{i}$ é o logaritmo da produção da i-ésima firma; $w_{i}$ é o vetor de logaritmos dos preços pagos pelos fatores de produção; $\beta$ é o vetor de parâmetros a serem estimados; $v_{i}$ é o termo de erro aleatório e $u_{i}$ é o termo de erro não negativo associado à ineficiência de custo da i-ésima firma. A medida de eficiência econômica de custo da i-ésima firma $\left(E E_{i}\right)$ pode, então, ser obtida pela razão entre o custo mínimo representado pela fronteira (com $u_{i}=0$ ) e o custo da firma, o que resulta em:

$$
E E_{i}=e^{-u i}
$$

Para identificar os fatores determinantes da eficiência de custo, aspecto de maior interesse na análise, adotou-se o modelo de um único estágio proposto por Battese e Coelli (1995). Esse modelo tem sido amplamente utilizado para analisar as variáveis determinantes dos diferenciais de eficiência das firmas que operam em um mesmo mercado (COELLI e FLEMING, 2004; RAHMAN e RAHMAN, 2008; CABRERA et al., 2010; MANJUNATHA et al., 2013; DONG et al., 2014; CARRER et al., 2015). De forma geral, os estudos empíricos especificam um conjunto de variáveis para estimar a fronteira de produção, custo ou lucro (a depender do interesse do pesquisador e dos dados disponíveis) e um vetor adicional de variáveis para explicar os diferenciais de eficiência/ineficiência das firmas da amostra. ${ }^{9}$

O termo de ineficiência $u$ assume uma distribuição normal truncada positiva com um parâmetro constante de escala $\sigma_{u}^{2}$ e um parâmetro m que depende de um vetor adicional de variáveis explicativas (determinantes dos diferenciais de eficiência/ineficiência). Assim, a partir da equação (1), é acrescentado um vetor de variáveis z para explicar os diferenciais de eficiência entre as firmas da amostra:

$$
u \sim N^{+}\left(\mu, \sigma_{u}^{2}\right) \operatorname{com} \mu=\delta z
$$

em que $z_{i}$ é um vetor de variáveis determinantes da ineficiência (e, consequentemente, da eficiência) das

9. Os trabalhos de Murillo-Zamorano (2004), Greene (2008) e Parmeter e Kumbhakar (2014) apresentam discussões detalhadas sobre os aspectos teóricos e aplicados dos diferentes modelos de fronteira e determinantes da eficiência. 
firmas e $\delta$ é um vetor de parâmetros associados às variáveis determinantes da ineficiência/eficiência que devem ser estimados.

Especificou-se uma forma funcional translog para representar a tecnologia de produção. Assim, pode-se representar a fronteira de custo em sua forma específica como:

$$
\begin{aligned}
& \ln \left(\frac{C}{w_{3}}\right)= \\
& \beta_{0}+\beta_{1} \ln \left(\frac{w_{1}}{w_{3}}\right)+\beta_{2} \ln \left(\frac{w_{2}}{w_{3}}\right)+ \\
& \beta_{y} \ln { }_{y}+\beta_{11} 1 / 2 \ln \left(\frac{w_{1}}{w_{3}}\right)^{2}+\beta_{12} \ln \frac{w_{1}}{w_{3}} \ln \frac{w_{2}}{w_{3}}+ \\
& \beta_{22} 1 / 2 \ln \left(\frac{w_{2}}{w_{3}}\right)^{2}+\beta_{y 1} \ln \ln _{y} \frac{w_{1}}{w_{3}}+\beta_{y 2} \ln \ln \frac{w_{2}}{w_{3}}+ \\
& \beta_{y y} 1 / 2 \ln _{y}^{2}+v+u
\end{aligned}
$$

As variáveis utilizadas na função de custo estão descritas na Tabela 1. Percebe-se, a partir de (4), que a variável "dispêndio" $\left(w_{3}\right)$ foi utilizada para impor a condição de homogeneidade linear nos preços da função custo. ${ }^{10}$ Os parâmetros relacionados a essa variável são obtidos por diferença:

$$
\begin{aligned}
& \beta_{3}=1-\left(\beta_{1}+\beta_{2}\right) \\
& \beta_{13}=-\beta_{11}-\beta_{12} \\
& \beta_{23}=-\beta_{12}-\beta_{22} \\
& \beta_{33}=-\beta_{13}-\beta_{23} \\
& \beta_{y 3}=-\beta_{y 1}-\beta_{y 2}
\end{aligned}
$$

A partir da equação (4) é acrescentado um vetor com quatro variáveis z (Tabela 1) para explicar os determinantes de ineficiência de custo das propriedades rurais da amostra:

$$
\mu_{i}=\delta_{1} z_{1 i}+\delta_{2} z_{2 i}+\delta_{3} z_{3 i}+\delta_{4} z_{4 i}
$$

Os parâmetros das equações (4) e (10) foram estimados simultaneamente por meio de procedimentos de máxima verossimilhança utilizando-se o pacote "frontier" (COELLI e HENNINGSEN, 2013) no software estatístico " $\mathrm{R}$ ".

10. É importante mencionar que a variável adotada para impor a restrição de homogeneidade linear nos preços não interfere nos resultados dos parâmetros e índices de eficiência estimados.

\subsection{Amostra e variáveis de análise}

A amostra desse estudo está concentrada no estado de São Paulo, dada a sua grande representatividade na produção citrícola brasileira $(74 \%$ do total produzido em 2013). Para calcular o tamanho da amostra de propriedades citrícolas, utilizou-se a divisão regional proposta por Neves (2010), que divide a citricultura do estado de São Paulo em cinco regiões: noroeste, norte, centro, sul e castelo. A partir dessa divisão, selecionaram-se as regiões central, sul e norte que, segundo dados do Lupa (2007), compreendem 9.370 propriedades rurais com produção de laranja (50\% do total no estado). Para calcular o tamanho da amostra, adotou-se o critério de amostragem aleatória simples. Obteve-se uma amostra de 98 propriedades rurais, com erro amostral de $10 \%$ e nível de confiança de $95 \%$.

Foram coletados dados por meio de entrevistas realizadas pessoalmente junto aos citricultores durante o período de março a setembro de 2014. Adotou-se um questionário estruturado, dividido em quatro blocos de questões: a) características estruturais da produção (uso de fatores, produção e tecnologia); b) aspectos de comercialização (preços e estruturas de governança); c) características dos produtores e d) ambiente institucional e expectativas.

A descrição das variáveis utilizadas para estimar a fronteira de custo e os determinantes da eficiência de custo pode ser observada no Quadro 1. Para uma descrição detalhada sobre a escolha das variáveis e outros procedimentos teóricos e metodológicos associados à fronteira de custo, ver Carrer e Souza Filho (2016). O presente estudo tem o foco principal na análise do efeito dos ajustes contratuais e das variáveis de controle (variáveis $z$ ) sobre a ineficiência de custo das propriedades rurais. No Quadro 1, além da variável "ajustes contratuais", estão três variáveis de controle dos determinantes da eficiência: "diversificação", "ferramentas de gestão" e "greening".

A variável "ajustes contratuais" consiste de um índice com valor de 0 a 6 que mede a ocorrência de até seis diferentes tipos de ajustes contratuais na venda de laranja nos anos-safra 2011/12, 2012/13 e 2013/14. Essa é a principal variável de interesse na análise econométrica, cuja hipótese foi apresentada e discutida na seção 2.

A variável "diversificação" consiste também de um índice, HHI, calculado a partir da área total e da área 
Quadro 1. Variáveis adotadas para estimar a fronteira de eficiência de custo e os determinantes da eficiência de custo

\begin{tabular}{|c|c|}
\hline Variável & Descrição \\
\hline Custo $(\mathrm{C})^{*}$ & $\begin{array}{l}\text { Gasto total com os fatores de produção mão de obra, capital, fertilizantes e defensivos (somatório } \\
\text { dos preços médios multiplicados pelas quantidades físicas utilizadas) }\end{array}$ \\
\hline Produção (y) & Número de caixas de 40,8 kg de laranja produzidas na safra 2013/14 \\
\hline Preço da mão de obra $\left(w_{1}\right)$ & $\begin{array}{l}\text { Gasto total com mão de obra dividido pela quantidade de horas trabalhadas na safra } 2013 / 14= \\
\text { preço da hora de trabalho }\end{array}$ \\
\hline Preço do capital $\left(\mathrm{w}_{2}\right)$ & $\begin{array}{l}\text { Somatório dos gastos com manutenção, depreciação, óleo diesel e energia elétrica dividido pela } \\
\text { quantidade de horas máquina utilizada na safra } 2013 / 14=\text { preço da hora máquina }\end{array}$ \\
\hline Dispêndio $\left(w_{3}\right)$ & $\begin{array}{l}\text { Gasto total com fertilizantes NPK + gasto total com defensivos (produtos fitossanitários) dividido } \\
\text { pelo número de pés de laranja em produção na safra 2013/14 }\end{array}$ \\
\hline Ajustes contratuais $\left(\mathrm{z}_{1}\right)$ & $\begin{array}{l}\text { Índice com valor de } 0 \text { a } 6 \text { que mede a ocorrência de até seis diferentes tipos de ajustes contratuais } \\
\text { na venda de laranja nos anos-safra 2011/12, 2012/13 e 2013/14: i) redução no preço acordado; } \\
\text { ii) retardamento na recepção da fruta; iii) dilatamento do prazo de pagamento; iv) redução da } \\
\text { quantidade contratada; v) não aquisição; vi) outro ajuste que gerou perda financeira considerável. }\end{array}$ \\
\hline Diversificação $\left(\mathrm{z}_{2}\right)$ & $\begin{array}{l}\text { Índice Herfindahl-Hirschman (HHI) calculado a partir da área total e da área com diferentes cul- } \\
\text { turas agropecuárias nas propriedades rurais. Apresenta valor entre } 0 \text { e } 1 \text { e, quanto mais próximo } \\
\text { de } 1 \text {, mais concentrada a produção rural em apenas uma cultura. }\end{array}$ \\
\hline Ferramentas de gestão $\left(\mathrm{z}_{3}\right)$ & $\begin{array}{l}\text { Índice com valor de } 0 \text { a } 7 \text { que mede o uso das seguintes ferramentas de gestão: i) planilhas eletrôni- } \\
\text { cas de custo; ii) registros eletrônicos de estoque de insumos; iii) registros eletrônicos de produção, } \\
\text { produtividade e incidência de doenças por talhão; iv) uso de sistemas informatizados e integrados } \\
\text { de gestão/sistemas de apoio à tomada de decisão; v) acesso à internet para acompanhamento do } \\
\text { mercado; vi) técnicas de agricultura de precisão; vii) certificaçôes de qualidade. }\end{array}$ \\
\hline Greening $\left(\mathrm{z}_{4}\right)$ & Variável obtida a partir do percentual de incidência de greening nos pomares em produção. \\
\hline
\end{tabular}

* Não estão incluídos custos com formação de pomar, custos associados ao uso da terra, custos de transporte e custos de oportunidade. Carrer e Souza Filho (2016) apresentam justificativas para a não inclusão de tais variáveis.

Fonte: Elaborado pelos autores.

com diferentes culturas agropecuárias nas propriedades rurais. A diversificação pode ser considerada uma estratégia de hedge, reduzindo o risco de dependência do agricultor de uma única atividade rural. Assim, o produtor que diversifica mais a sua produção reduz a dependência da receita da propriedade com relação à citricultura. Ademais, permite economia de escopo, dada a redução na ociosidade de fatores de produção, capital e trabalho, cujo uso poderia ser melhor distribuído em diversas culturas. Como os preços da caixa de laranja são bastante baixos nos anos-safra 2011/12 e 2012/13, é possível que agricultores com produção diversificada tenham utilizado o caixa gerado em outras atividades para cobrir os prejuízos da citricultura, não tendo reduzido consideravelmente seus investimentos nessa última atividade. A diversificação pode ainda resultar em melhor uso de mão de obra e esforços gerenciais, que, em propriedades com maior diversificação, são mais bem distribuídos entre as atividades ao longo do ano (COELLI e FLEMING, 2004; MANJUNATHA et al., 2013). Assim, espera-se que propriedades rurais com produção diversificada sejam economicamente mais eficientes do que aquelas focadas exclusivamente na citricultura.
A variável "ferramentas de gestão" mensura a adoção de sete ferramentas gerenciais para a tomada de decisões técnicas e econômicas na produção citrícola. $\mathrm{O}$ uso de ferramentas de gestão é fundamental para o planejamento e controle das atividades estratégicas e operacionais. Por exemplo, ao adotar planilhas eletrônicas para controle de custos, é possível estabelecer objetivos de redução de custo a partir de informações contábeis do passado, bem como monitorar o cumprimento de tais objetivos. Ferramentas de acesso à internet e de agricultura de precisão têm efeito semelhante, pois possibilitam um maior controle sobre o desempenho econômico da firma. Assim, produtores que adotam um número maior de ferramentas de gestão conseguem coordenar e otimizar processos produtivos, bem como melhorar o uso e a alocação de fatores de produção. Carrer et al. (2015) constataram que essas ferramentas têm impacto positivo e estatisticamente significativo sobre a eficiência técnica/produtividade das propriedades citrícolas. Portanto, espera-se que essa variável também seja importante para explicar a eficiência de custo das propriedades rurais.

Por sua vez, a variável "greening" visa controlar o efeito da incidência dessa doença sobre a eficiência 
Tabela 1. Estatísticas descritivas das variáveis adotadas na análise econométrica

\begin{tabular}{lcccc}
\hline \multicolumn{1}{c}{ Variável } & Média & Desvio padrão & Mínimo & Máximo \\
\hline Custo $(\mathrm{C})(\mathrm{em} \mathrm{R}$ ) & $925.449,02$ & $1.291 .540,71$ & 23.412 & 7.091 .490 \\
Produção (y) (em caixas) & $59.281,91$ & $82.677,26$ & 600,00 & $500.000,00$ \\
Preço da mão de obra $\left(\mathrm{w}_{1}\right)(\mathrm{em} \mathrm{R} \$)$ & 8,41 & 1,36 & 6,11 & 11,74 \\
Preço do capital $\left(\mathrm{w}_{2}\right)(\mathrm{em} \mathrm{R} \$)$ & 18,37 & 3,01 & 12,1 & 26,35 \\
Dispêndio $\left(\mathrm{w}_{3}\right)(\mathrm{em} \mathrm{R}$ ) & 5,32 & 2,16 & 0,93 & 11,57 \\
Ajustes contratuais $\left(\mathrm{z}_{1}\right)$ & 1,43 & 1,68 & 0 & 6 \\
Diversificação $\left(\mathrm{z}_{2}\right)$ & 0,60 & 0,27 & 0,15 & 1 \\
Ferramentas de gestão $\left(\mathrm{z}_{3}\right)$ & 3,18 & 2,04 & 0 & 7 \\
Greening $\left(\mathrm{z}_{4}\right)$ & 0,11 & 0,15 & 0 & 0,8 \\
\hline
\end{tabular}

Fonte: Elaborado pelos autores.

de custo das propriedades. ${ }^{11}$ Diante dos efeitos negativos do greening na produção citrícola e do aumento nos gastos com defensivos e inspeções nas propriedades com alta incidência, espera-se encontrar efeito negativo dessa variável sobre a eficiência de custo das propriedades.

As estatísticas descritivas das variáveis incluídas na análise podem ser observadas na Tabela 1 . Na média da amostra, o custo de produção foi de $\mathrm{R} \$ 955.449,02$, com mínimo de $\mathrm{R} \$ 23.412$, máximo de $\mathrm{R} \$ 7.091 .490,00$ e desvio padrão de $\mathrm{R} \$ 1.291 .540,71$. A produção média, por sua vez, foi de 59.282 caixas de 40,8 kg. Os gastos com defensivos e fertilizantes (variável dispêndio) representaram, na média da amostra, a maior parcela dos custos (58\%), sendo que o índice de preço médio dos defensivos e fertilizantes por planta em produção foi de $\mathrm{R} \$ 3,22$. A mão de obra representou, em média, $23 \%$ do custo das propriedades e o preço médio da hora de mão de obra foi de $\mathrm{R} \$ 8,41$. O gasto médio por hora máquina foi de $\mathrm{R} \$ 18,37$ e o capital representou, em média, $19 \%$ do custo das propriedades. Percebe-se que, na média da amostra, os citricultores foram afetados em algum momento por 1,43 dos 6 problemas contratuais investigados, adotam 3,18 ferramentas de gestão e seus pomares possuem $11 \%$ de incidência de greening. O índice HHI para diversificação/concen-

11. O greening (Huanglongbing/HLB) é uma doença que foi identificada pela primeira vez na citricultura brasileira em 2004. Ele é causa de grande preocupação para os citricultores devido à velocidade em que se espalha do seu lugar original para outras regiões. As árvores jovens contaminadas pelo greening não produzem e as árvores que produzem têm grande perda no número de frutos. Pomares com alta incidência da doença devem ser completamente erradicados, uma vez que praticamente todas as plantas, incluindo aquelas sem sintomas, podem estar contaminadas (NEVES, 2010). tração da produção apresentou valor médio de 0,60, com mínimo de 0,15 e máximo de 1 . Vale lembrar que, quanto mais próximo da unidade, mais concentrada a produção rural em poucas culturas (ou, no limite, apenas uma).

\section{Análise dos resultados}

A Tabela 2, a seguir, apresenta os resultados do modelo econométrico de fronteira e determinantes da ineficiência de custo.

Pelo teste de razão de máxima verossimilhança, pode-se rejeitar a hipótese nula de que não há ineficiência de custo na produção de laranja das propriedades analisadas com $1 \%$ de significância estatística. Portanto, o modelo econométrico com ineficiência de custo é mais adequado do que os modelos tradicionais de custo estimados por MQO. Foram testadas também hipóteses em torno da forma funcional adotada para representar a tecnologia de produção, sendo que a translog mostrou-se mais adequada. Por sua vez, o parâmetro de variância $\gamma$ apresentou valor de 0,678 e significância estatística ao nível de $1 \%$, indicando que o termo de ineficiência é importante para explicar os desvios das propriedades com relação à fronteira de custo. As condições de monotonicidade e concavidade nos preços dos fatores foram checadas e satisfeitas para a média da amostra. ${ }^{12}$

Dentre os 15 parâmetros estruturais (b's) da fronteira de custo, seis se mostraram estatisticamente significativos. A partir desses parâmetros estruturais é

12. Foram também calculadas as correlações entre as variáveis para identificar a existência de multicolinearidade no modelo, a qual foi rejeitada. 
Tabela 2. Parâmetros estimados da fronteira de custo e determinantes da ineficiência de custo das propriedades rurais

\begin{tabular}{|c|c|c|c|}
\hline Variável & Parâmetro & Coeficiente & $\operatorname{Pr}(>|z|)$ \\
\hline Constante & $\beta_{0}$ & $-0,2842$ & $0,000^{* * *}$ \\
\hline $\operatorname{lnw}_{1}$ (preço mão de obra) & $\beta_{1}$ & 0,0597 & 0,310 \\
\hline $\ln w_{2}$ (preço capital) & $\beta_{2}$ & 0,6083 & $0,000^{* * *}$ \\
\hline $\ln w_{3}$ (dispêndio) & $\beta_{3}$ & 0,3320 & $0,000^{* * *}$ \\
\hline lny (produção) & $\beta_{\mathrm{y}}$ & 0,9273 & $0,000^{* * *}$ \\
\hline $\ln w_{1} \times \ln w_{1}$ & $\beta_{11}$ & $-0,3117$ & 0,872 \\
\hline $\ln w_{1} \times \ln w_{2}$ & $\beta_{12}$ & 0,3771 & 0,389 \\
\hline $\ln w_{1} \times \ln w_{3}$ & $\beta_{13}$ & $-0,0654$ & 0,256 \\
\hline $\ln w_{2} \times \ln w_{2}$ & $\beta_{22}$ & $-0,6180$ & 0,449 \\
\hline $\ln w_{2} \times \ln w_{3}$ & $\beta_{23}$ & 0,2409 & 0,395 \\
\hline $\ln w_{3} \times \ln w_{3}$ & $\beta_{33}$ & $-0,1755$ & 0,332 \\
\hline $\ln y \mathrm{x} \ln y$ & $\beta_{y y}$ & 0,1000 & $0,000^{* * *}$ \\
\hline $\ln y x \ln w_{1}$ & $\beta_{\mathrm{y} 1}$ & $-0,0575$ & 0,892 \\
\hline $\ln y x \ln w_{2}$ & $\beta_{y 2}$ & $-0,0036$ & 0,962 \\
\hline $\ln y x \ln w_{3}$ & $\beta_{y 3}$ & 0,0611 & $0,092^{*}$ \\
\hline \multicolumn{4}{|l|}{ Determinantes ineficiência de custo } \\
\hline $\mathrm{z}_{1}$ (ajustes contratuais) & $\delta_{1}$ & 0,1487 & $0,000^{* * *}$ \\
\hline $\mathrm{z}_{2}$ (diversificação/concentração) & $\delta_{2}$ & 0,2964 & $0,030^{* *}$ \\
\hline $\mathrm{z}_{3}$ (ferramentas gestão) & $\delta_{3}$ & $-0,0975$ & $0,002^{* * *}$ \\
\hline $\mathrm{z}_{4}$ (greening) & $\delta_{4}$ & 0,0868 & 0,731 \\
\hline \multicolumn{4}{|c|}{ Parâmetros de variância } \\
\hline$\sigma_{\mathrm{s}}^{2}$ & & 0,0697 & $0,000^{* * *}$ \\
\hline$\gamma$ & & 0,6780 & $0,000^{* * *}$ \\
\hline Log-Likelihood & & 14,356 & \\
\hline Chi-squared & & 64,504 & $0,000 * * *$ \\
\hline Eficiência média & & 0,777 & \\
\hline $\mathrm{N}=98$ & & & \\
\hline
\end{tabular}

* Significativo ao nível de $10 \%$; ** Significativo ao nível de $5 \%$; *** Significativo ao nível de $1 \%$. Fonte: Elaborado pelos autores.

possível calcular os índices de economias de escala, as parcelas ótimas dos fatores de produção e as elasticidades de substituição entre os fatores. Entretanto, apresenta-se aqui apenas a análise do efeito da ocorrência de ajustes contratuais e das variáveis de controle sobre a eficiência de custo das propriedades rurais. ${ }^{13} \mathrm{~A}$ distri-

13. Carrer e Souza Filho (2016) analisaram a escala ótima de produção, as parcelas ótimas dos fatores de produção e as elasticidades de substituição entre os fatores a partir da estimativa econométrica de uma fronteira de custo translog. Os autores identificaram que a escala ótima (escala de custo médio mínimo) de produção de laranja está entre 150.000-300.000 caixas e que há considerável espaço para redução no custo de produção das propriedades. Ademais, constatou-se também que as propriedades rurais mais eficientes em custo são mais intensivas em capital (e menos em trabalho). O presente artigo adota a mesma base de dados e faz uma análise complementar àquela realizada por Carrer e Souza Filho (2016). buição dos índices de eficiência de custo das propriedades rurais pode ser observada na Tabela 3 .

Tabela 3. Distribuição dos índices de eficiência de custo das 98 propriedades rurais analisadas

\begin{tabular}{cc}
\hline $\begin{array}{c}\text { Índices de eficiência } \\
\text { de custo }\end{array}$ & $\begin{array}{c}\text { Número de propriedades } \\
\text { rurais }\end{array}$ \\
\hline$<50 \%$ & 8 \\
$50-70 \%$ & 19 \\
$70.01-80 \%$ & 18 \\
$80.01-90 \%$ & 23 \\
$>90.01 \%$ & 30 \\
\hline Eficiência média & 0,777 \\
Desvio padrão & 0,159 \\
Máximo & 0,967 \\
Mínimo & 0,374 \\
\hline
\end{tabular}

Fonte: Elaborado pelos autores. 
Os índices de eficiência de custo das propriedades rurais analisadas apresentaram-se entre o mínimo de $37,4 \%$ e o máximo de $96,7 \%$, com média de $77,7 \%$ e desvio padrão de $15,9 \%$. Neste modelo, a firma mais eficiente da amostra opera com possibilidade de reduzir seu custo em apenas 3,3\% diante da mesma produção e do mesmo vetor de preços pagos pelos fatores. Já a firma menos eficiente da amostra poderia operar com um custo de produção $62,6 \%$ mais baixo caso utilizasse os fatores de forma mais eficiente e/ou combinasse-os de forma ótima diante de seus preços relativos. Ademais, verifica-se que, em média, as propriedades rurais analisadas poderiam reduzir o custo em consideráveis $22,3 \%$ apenas alterando a combinação dos fatores de produção e utilizando-os de forma mais eficiente. Nota-se, também, que há considerável diferença entre os índices de eficiência de custo das propriedades, com $27,5 \%$ da amostra operando com eficiência inferior a $70 \%$ vis à vis $30,6 \%$ operando com eficiência superior a 90\%. Clemente et al. (2015) e Carrer et al. (2015) também analisaram índices de eficiência e seus determinantes com base em dados de propriedades citrícolas. Clemente et al. (2015) adotaram um modelo de análise envoltória de dados (DEA) e constataram que a eficiência técnica média das propriedades foi de $79 \%$ e que nove propriedades estavam operando com eficiência de $100 \%$. Os autores verificaram também que a escolaridade e a experiência dos produtores exercem impacto positivo e significativo sobre os índices de eficiência técnica das propriedades. Carrer et al. (2015) utilizaram a abordagem de fronteira estocástica com uma tecnologia de produção translog e constataram que a eficiência técnica média das propriedades foi de $75 \%$, com mínimo de $29 \%$ e máximo de $97 \%$. Os autores encontraram ainda evidências de que o uso de ferramentas gerenciais, a formação de expectativas favoráveis e a adoção de contratos de longo prazo têm efeito positivo e estatisticamente significativo sobre os índices de eficiência técnica das propriedades. O presente estudo se diferencia dos estudos mencionados ao trabalhar com uma fronteira de custo e, consequentemente, estimar índices de eficiência econômica de custo. Ademais, preocupa-se, prioritariamente, em investigar como aspectos das relações comerciais entre citricultores e indústria processadora de suco podem afetar o uso e a alocação dos fatores de produção nas propriedades citrícolas.

Dentre as variáveis de controle utilizadas no modelo de determinantes da eficiência de custo, o uso de ferramentas de gestão e a diversificação da produção apresentaram significância estatística e sinal esperado. Conforme discutido na seção três e constatado nos resultados do modelo estimado, o uso de ferramentas de gestão é importante para otimizar o processo de tomada de decisões dos produtores rurais. Essas ferramentas melhoram o planejamento e controle da produção e, consequentemente, a eficiência no uso e na alocação dos fatores de produção nas propriedades citrícolas. Esse resultado está em consonância com aquele encontrado por Carrer et al. (2015), evidenciando que o uso de ferramentas de gestão, além de afetar positivamente a eficiência técnica, também afeta a eficiência alocativa das propriedades citrícolas. O índice de diversificação/concentração da produção (quanto mais próximo de um, mais concentrada a produção rural) apresentou efeito negativo sobre a eficiência de custo das propriedades rurais. A diversificação da produção apresentou elevada correlação com a área total (conjunto de todas as culturas) das propriedades, o que indica que propriedades com maior nível de diversificação da produção são também propriedades de maior porte no conjunto de atividades rurais. ${ }^{14}$ Portanto, além das vantagens da diversificação já mencionadas na seção três (economia de escopo e melhor distribuição no uso dos fatores de produção ao longo do ano), pode-se dizer que estas propriedades, por comprarem maior volume de insumos, obtêm economias de escopo relacionadas às suas transações na compra de insumos (pagamento de preços mais baixos e outras). Esse resultado está alinhado à hipótese de Neves (2010) de que a diversificação é uma estratégia gerencial com potencial de aumentar a eficiência nas propriedades citrícolas do estado de São Paulo.

O parâmetro da variável ajustes contratuais, que é de maior interesse na análise, apresentou efeito positivo e estatisticamente significativo ao nível de $1 \%$ sobre a ineficiência de custo das propriedades (negativo sobre a eficiência). O efeito marginal da variável, calculado para a média da amostra, adotando-se o procedimento proposto por Olsen e Henningsen (2011),

14. A diversificação da produção apresenta correlação com a área total (conjunto de todas as culturas) das propriedades, o que indica que propriedades com maior nível de diversificação da produção são também propriedades de maior porte no conjunto de atividades rurais. Para comprovar, regressou-se a área total com o índice de diversificação/concentração, obtendo-se o sinal esperado e significância estatística ao nível de $1 \%$. 
mostra que cada ajuste contratual reduz a eficiência de custo em $2,26 \%$, ceteris paribus. Ou seja, um produtor que teve os seis ajustes contratuais investigados nos últimos três anos tende a operar sua propriedade com eficiência de custo $13,56 \%$ inferior à de um produtor que não teve os ajustes investigados. Esse resultado comprova a hipótese central do estudo, estabelecida na seção 2 .

Assim, é plausível argumentar que a ocorrência de ajustes contratuais nos últimos três anos gerou insegurança para os produtores e, consequentemente, desincentivos à adoção criteriosa de tecnologias de produção, ferramentas de gestão e ao uso adequado de insumos. Esses fatores afetam diretamente na eficiência técnica (componente da eficiência de custo) das propriedades rurais. A ausência de incentivos típicos de contratos neoclássicos tende ainda a aumentar os custos de transação e gerar problemas de alocação dos fatores de produção. Diante das expectativas desfavoráveis resultantes da ocorrência de ajustes contratuais subsequentes, os citricultores deixam de acessar informações e de utilizar ferramentas que poderiam auxiliá-los na alocação dos fatores de produção diante de seus preços relativos.

O resultado final dos efeitos acima mencionados é uma redução na eficiência econômica da produção citrícola dos citricultores mais afetados por ajustes contratuais, conforme constatado no modelo econométrico estimado. Poder-se-ia argumentar que esses citricultores deveriam deixar a atividade devido à ineficiência econômica. Contudo, devido ao elevado custo de saída, uma parcela dos produtores tende a continuar operando na atividade por mais algumas safras, mesmo com menor eficiência econômica. ${ }^{15}$ Isso torna a questão dos ajustes contratuais ainda mais crítica, visto que o produtor rural pode aumentar seu nível de endividamento para conseguir continuar a produção, chegando, em última instância, a perder todo seu patrimônio.

15. A idade média dos pomares dos citricultores com índices de eficiência inferiores a $70 \%$ (baixa eficiência) é de oito anos. Isso indica que os pomares desses produtores estão na fase biológica de alta produção e ainda possuem aproximadamente seis anos para continuar produzindo. O custo de deixar a atividade com os pomares nessa fase produtiva é consideravelmente alto.

\section{Conclusões}

Esse artigo teve o objetivo principal analisar o efeito da ocorrência de ajustes contratuais na venda da laranja sobre a eficiência de custo de propriedades citrícolas. Por meio da estimativa de uma fronteira de custo translog, foi observado que, na média da amostra, a ineficiência de custo é de $22,3 \%$, indicando potencial de redução de custos sem alterar o volume de produção e/ou o uso dos fatores nas propriedades. Verificou-se que a ocorrência de ajustes contratuais afeta negativamente a eficiência de custo das propriedades, confirmando-se, assim, a principal hipótese do estudo. Ademais, propriedades com produção rural mais diversificada e gerenciadas por agricultores que adotam um maior número de ferramentas de gestão possuem maior eficiência em custo na citricultura.

Do ponto de vista teórico, a principal contribuição do trabalho está na constatação de que fatores geradores de custos nas transações de venda do produto (ajustes contratuais não antecipados diante de distúrbios) afetam a alocação dos recursos dentro das firmas, reduzindo a eficiência econômica. A principal implicação desse resultado é a necessidade do desenvolvimento de formas híbridas de governança que reduzam a ocorrência de distúrbios altamente consequentes em contratos neoclássicos, reduzindo custos de transação e gerando incentivos para melhor alocação dos fatores de produção. Caso contrário, a hierarquia, ou o mercado, tornam-se as estruturas de governança mais viáveis. No caso do SAG citrícola, a determinação, em 2012, do Conselho Administrativo de Defesa Econômica (Cade) para a formação de um conselho com representantes das empresas processadoras e dos citricultores não deixa de ser uma proposta para desenvolvimento de uma nova governança. ${ }^{16}$ Nessa proposta, está explícita

16. O Consecitrus é um conselho formado por organizações representantes dos citricultores e da indústria processadora de suco que tem o objetivo central de definir um modelo de precificação da caixa de laranja baseado em princípios de repartição de sobras a partir da participação de cada agente na formação do preço final do suco de laranja. A criação do Consecitrus foi determinada a partir de um Termo de Compromisso de Desempenho (TCD) acordado entre o Conselho Administrativo de Defesa da Concorrência (CADE) e as empresas Citrovita e Citrosuco, que fundiram suas operações em 2011. Esse modelo ainda estava sendo discutido entre os agentes envolvidos quando esse texto foi concluído. 
a necessidade de reduzir a assimetria de informação e de poder de barganha existente entre as partes.

Os resultados empíricos desse estudo têm implicação para a formulação de políticas públicas. Ajustes contratuais frequentes, associados ao exercício de poder de barganha e falhas institucionais, causam ineficiência econômica e, consequentemente, redução de bem-estar. Uma melhor regulação das relações comerciais, tal que haja compensação para o elevado poder de barganha da agroindústria processadora, reduziria a ocorrência de ajustes altamente consequentes. Tal redução, por sua vez, pode se refletir em maior eficiência econômica na produção de laranja.

Para estudos futuros, recomenda-se a análise do impacto da criação de novas governanças na redução, ou aumento, da ocorrência de distúrbios e suas consequências para os contratos neoclássicos. Análises de eficiência com dados em painel e o desenvolvimento de outros indicadores para mensurar a ocorrência de ajustes contratuais são também desejáveis.

\section{Referências}

AZEVEDO, P. F. Integração vertical e barganha. 1996. Tese (Doutorado em Economia) - Faculdade de Economia, Administração e Contabilidade, Universidade de São Paulo, São Paulo.

BATTESE, G. E. e COELLI, T. J. A model for technical inefficiency effects in a stochastic frontier production function for panel data. Empirical Economics, v. 20, p. 325-332, 1995.

BRASSELLE, A., GASPART, F. e PLATTEAU, J. Land tenure security and investment incentives: Puzzling evidence from Burkina Faso. Journal of Development Economics, v. 67, n. 2, p. 373-418, 2002.

BOWEN, H. P. e DE CLERCQ, D. Institutional context and the allocation of entrepreneurial effort. Journal of International Business Studies, v. 39, p. 747-767, 2008.

CABRERA, V. E., SOLÍS, D. e CORRAL, J. Determinants of technical efficiency among dairy farms in Wisconsin. Journal of Dairy Science, v. 93 n. 1, p. 387-393, 2010.

CADE - Conselho Administrativo de Defesa da Concorrência. Ato de concentração ño 08012.003065/201221. Constituição do Consecitrus, 2014.

CARRER, M. J. e SOUZA FILHO, H. M. Economias de escala e eficiência econômica na produção de laranja no Estado de São Paulo. Revista de Economia e Sociologia Rural, v. 54, n. 1, p. 51-70, 2016.
CARRER, M. J. et al. Farm Management Information Systems (FMIS) and technical efficiency: an analysis of citrus farms in Brazil. Computers and Electronics in Agriculture, v. 119, p. 105-111, 2015.

CLEMENTE, F., GOMES, M. F. M. e LÍRIO, V. S. Análise da eficiência técnica de propriedades citrícolas do estado de São Paulo. Economia Aplicada, v. 19, n. 1, p. 63-79, 2015.

COELLI, T. J. e FLEMING, E. Diversification economies and specialization efficiencies in a mixed food and coffee smallholder farming system in Papua New Guinea. Agricultural Economics, v. 31, n. 2-3, p. 229-239, 2004.

COELLI, T. J. e HENNINGSEN, A. Frontier: Stochastic Frontier Analysis. R package version 1.1. Disponível em: $<$ http://CRAN.R-project.org/package $=$ frontier $>$. 2013.

DEQUECH, D. Economic institutions: explanations for conformity and room for deviation. Journal of Institutional Economics, v. 9, p. 81-108, 2013.

DONG, Y., HAMILTON, R. e TIPPETT, M. Cost efficiency of the Chinese banking sector: a comparison of stochastic frontier analysis and data envelopment analysis. Economic Modelling, v. 36, p. 298-308, 2014.

FIGUEIREDO, A. M., SOUZA FILHO, H. M. e PAULILLO, L. F. O. Análise das margens e transmissão de preços no Sistema Agroindustrial do suco de laranja no Brasil. Revista de Economia e Sociologia Rural, v. 51, n. 2, p. 331-350, 2013.

FULGINITI, L. E., PERRIN, R. K. e YU, B. Institutions and agricultural productivity in Sub-Saharan Africa. Agricultural Economics, v. 31, p. 169-189, 2004.

GREENE, W. H. The econometric approach to efficiency analysis. In: FRIED, H. O., KNOX-LOVELL, C. A. e SCHMIDT, S. S. (Ed.) The measurement of productive efficiency and productivity growth. Oxford University Press, 2008.

KLEIN, B., CRAWFORD, R. G. e ALCHIAN, A. A. Vertical Integration, Appropriable Rents, and the Competitive Contracting Process. Journal of Law and Economics, v. 21, n. 2, p. 297-326, 1978.

KLEIN, P. G. e LUU, H. Politics and productivity. Economic Inquiry, v. 41, n. 3, p. 433-447, 2003.

LEVANTAMENTO CENSITÁRIO DAS UNIDADES DE PRODUÇÃO AGROPECUÁRIA DO ESTADO DE SÃO PAULO - LUPA 2007/08. Disponível em: < http://www. cati.sp.gov.br/projetolupa>. 
MANJUNATHA, A. V., ANIK, A. R. e SPEELMAN, S. Impact of land fragmentation, farm size, land ownership and crop diversity on profit and efficiency of irrigated farms in India. Land Use Policy, v. 31, p. 397405, 2013.

MARINO, M. K. e AZEVEDO, P. F. Avaliação da intervenção do sistema brasileiro de defesa da concorrência no sistema agroindustrial da laranja. Gestão E Produção, v. 10, n. 1, p. 35-46, 2003.

MELlO, F. O. T. e PAUlillo, L. F. Análise do alinhamento entre os atributos das transações e as formas de governança empregadas na citricultura. Gestão E Produção, v. 16, n. 3, p. 507-523, 2009.

MICHLER, J. D. e SHIVELY, G. E. Land tenure, tenure security and farm efficiency: panel evidence from the Philippines. Journal of Agricultural Economics, v. 66, n. 1, p. 155-169, 2015.

MURILLO-ZAMORANO, L. R. Economic efficiency and frontier techniques. Journal of Economic Surveys, v. 18, n. 1, p. 33-77, 2004.

NEVES, M. F. (Org.) O retrato da citricultura brasileira. 1. ed. São Paulo: CitrusBR, 2010.

NORTH, D. Economic performance through time. The American Economic Review, v. 84, n. 3, p. 359-368, 1994.

OLSEN, J. V. e HENNINGSEN, A. Investment utilization and farm efficiency in danish agriculture. FOI Working Paper 2011/13, Institute of Food and Resource Economics, University of Copenhagen, 2011. < http:// econpapers.repec.org/RePEc:foi:wpaper:2011_13>.

ORELLANO, V. et al. Land invasions, insecure property rights and production decisions. Journal of Agricultural Economics, v. 66, n. 3, p. 660-671, 2015.

PARMETER, C. F. e KUMBHAKAR, S. C. Efficiency analysis: a primer on recent advances. Foundations and Trends $®$ in Econometrics, v. 7, n. 3-4, p. 191-385, 2014.

PAUlillo, L. F. O., ALMEIDA, L. M. M. C. e FERRANTE, V. L. S. B. Os entraves organizacionais no setor agroindustrial citrícola do estado de São Paulo. Organizações Rurais \& Agroindustriais, v. 9, n. 2, p. 256271, 2007.
PAUlillO, L. F. O. E. e ALMEIDA, L. M. M. C. A coordenação agroindustrial citrícola brasileira e os novos recursos de poder: dos políticos aos jurídicos. Organizações Rurais \& Agroindustriais, v. 11, n. 1, p. 58-74, 2009.

PERRY, M. K. Vertical integration: determinants and Effects. In: SCHMALENSEE, R. e WILLING, R. D. Handbook of industrial organization. Elsevier Science Publishers, 1989.

RAHMAN, S. e RAHMAN, M. Impact of land fragmentation and resource ownership on productivity and efficiency: the case of rice producers in Bangladesh. Land Use Policy, v. 26, p. 95-103, 2008.

ROOKS, G., RAUB, W. e TAZELAAR, F. Ex Post Problems in Buyer-Supplier Transactions: Effects of Transaction Characteristics, Social Embeddedness, and Contractual Governance. Journal of Management Governance, v. 10, p. 239-276, 2006.

SOUZA FILHO, H. M. e PAULILlO, L. F. Public policies, transaction costs and access to commodity chain markets. Roma: ONU, 2005. Working paper of the Food Agricultural Organization.

SOUZA FILHO, H. M., BORELLA, M. L. e PAULILLO, L. F. O. Manifestação da Associtrus sobre o modelo de parametrização e de divisão de riscos e retorno na cadeia citrícola brasileira. Departamento de Engenharia de Produção - UFSCar, 2013. (Mimeo)

WILLIAMSON, O. E. The economic institutions of capitalism: firms, markets, relational contracting. New York: The Free Press, 1985.

Comparative economic organization: the analysis of discrete structural alternatives. Administrative Science Quarterly, v. 36, p. 269-296, 1991.

. The mechanisms of governance. New York, Oxford: Oxford University Press, 1996.

YASAR, M., PAUL, C. J. M. e WARD, M. Property Rights Institutions and Firm Performance: A CrossCountry Analysis. World Development, v. 39, n. 4, p. 648661, 2011.

Todo o conteúdo deste periódico, exceto onde estiver identificado, está licenciado sob uma Licença Creative Commons (cc by 4.0). 